\title{
UPAYA PELESTARIAN BUDAYA DI TAMAN BUDAYA SAGATI
}

\author{
Fauziah Hanum ${ }^{1}$, Dadang Suganda ${ }^{1}$, Eng. Budi Muljana ${ }^{1}$, Awaludin Nugraha ${ }^{2}$ \\ ${ }^{1}$ Sekolah Pascasarjana, Universitas Padjajaran, Jl. Dipatiukur No. 35 \\ ${ }^{2}$ Fakultas Ilmu Budaya, Universitas Padjajaran, Jl. Dipatiukur No. 35 \\ fh.hanum@gmail.com,dadang.suganda@unpad.ac.id,budi.muljana@unpad.ac.id, awaludin.nugraha@unpad.ac.id
}

\begin{abstract}
ABSTRAK
Kabupaten Pangandaran merupakan salah satu destinasi tujuan wisata unggulan dari Provinsi Jawa Barat. Selain dikenal dengan wisata alamnya, tersimpan pula potensi budaya yang belum sempat dikembangkan dan keberadaaanya terlupakan. Tujuan dari penelitian ini adalah untuk mengetahui bagaimana kegiatan pemberdayaan masyarakat dan kearifan lokal yang diterapkan oleh masyarakat di Kabupaten Pangandaran khususnya di Taman Budaya Sagati, Desa Margacinta sebagai salah satu upaya untuk pelestarian budaya. Penelitian ini merupakan penelitian kualitatif dengan metode deskriptif. Data diperoleh melalui studi literatur, wawancara dan pengamatan langsung. Hasil penelitian menunjukan bahwa Taman Budaya Sagati memiliki nilai lebih yang dapat menjadi keunggulan saing dalam hal sumber daya, ide dan inovasi dikarenakan kegiatan pemberdayaan dan penerapan kearifan lokal dalam kehidupan masyarakatnya. Namun dalam praktik pengelolaannya masih mengalami banyak kendala sehingga perlu adanya kolaborasi dengan berbagai pihak agar menjadi lebih baik lagi.
\end{abstract}

Kata kunci; pelestarian budaya, pemberdayaan masyarakat, kearifan lokal

\section{CULTURAL PRESERVATION AT TAMAN BUDAYA SAGATI}

\begin{abstract}
Kabupaten Pangandaran is one of the top tourist destination at West Java Province. In addition to it's nature based tourism, there is also a cultural potention for tourism that has not been developed even once had almost forgotten. This study is aimed at finding out how empowerment and community participation have been implemented by locals at Kabupaten Pangandaran especially Taman Budaya Sagati, Margacinta Village as one of their efforts to preserve culture. This research is a qualitative study with a descriptive method. The data for this research was gathered through literature studies, interviews and direct observation. The results showed that Sagati Cultural park has more value that can be a competitive advantage in resource, ideas and innovation because of the activities of empowerment and application of local wisdom in the lives of its people. But in the practice of management is still experiencing many obstacles so that the need for collaboration with various parties to be even better.
\end{abstract}

Key words; cultural preservation, community empowement, community participation, local wisdom

\section{PENDAHULUAN}

Kebudayaan adalah seluruh gagasan dan karya manusia yang muncul dari kebiasaannya sehari-hari yang menjadi sesuatu yang berulang lalu dikarenakan berbeda menjadi sebuah hal yang unik (Nahak 2019). Sektor pariwisata secara makro merupakan industri yang mendorong pertumbuhan dan inovasi dengan cepat. Budaya merupakan salah satu bidang yang menjadi produk bagi kegiatan Pariwisata. Budaya dalam kajian terkait pariwisata adalah segala bentuk pengkonsumsian dari seni, warisan atau peninggalan dari masa lampau (dapat berupa bangunan atau apapun), cerita rakyat dan berbagai macam manifestasi penerjemahan konteks budaya lainnya yang dilakukan oleh wisatawan (Markwick 2018).

Provinsi Jawa Barat adalah salah satu provinsi di Indonesia yang memiliki banyak potensi untuk bidang Pariwisata, khususnya terkait dengan alam, seni dan budaya, kuliner, religi dan lainnya (Ranawati 2019). Potensi tersebut sangatlah tepat untuk dimanfaatkan terkait dengan bidang pariwisata. Potensi budaya dan kearifan lokal merupakan salah satu bagian dari produk hasil kreatifitas yang memiliki nilai tinggi (Sugiyarto and Amarul 2018). Bentuk pemanfaatannya yaitu salah satunya dengan pembuatan atau pembentukan desa wisata. Potensi desa wisata ini perlu mendapat pengembangan dan perhatian sehingga akan dapat terlaksana dan termaksimalkan dalam rangka membantu meningkatkan kesejahteraan masyarakat tersebut (Darto 2017).

Pembangunan Provinsi Jawa Barat merujuk pada arahan gubernur secara umum diarahkan kepada pengembangan industri pariwisata, digitalisasi dan peningkatan ekonomi kreatif (Ranawati 2019). Hal ini berdasakan kepada tingginya potensi pariwisata yang tersebar di kabupaten/kota dalam kajian yang dibuat oleh Badan Perencanaan Daerah Provinsi Jawa Barat (Ranawati 2019). Pariwisata juga menjadi salah satu sektor andalan untuk meningkatkan pertumbuhan ekonomi Provinsi Jawa Barat (Adriani 2017). 
Disamping itu cantumkan pula dalam RIPPARPROV dan RPJMD Provinsi Jawa Barat Tahun 2015-2025 bahwa Provinsi Jawa Barat dipersiapkan menjadi destinasi pariwisata dunia yang terintegrasi, berkelanjutan dan menjunjung tinggi nilai budaya (Adriani 2017).

Pengembangan destinasi dan infrastruktur terkait pariwisata merupakan salah satu dari 10 prioritas Rencana Kerja Pemerintah Daerah Provinsi Jawa Barat untuk tahun 2020 (Syarifah 2019). Kegiatan pembangunan beserta pengembangan ini juga akan mendorong tumbuhnya kebersamaan, kemerataan nilai dan keberlanjutan hidup yang lebih baik (Rahmi 2016).

Kabupaten Pangandaran adalah salah satu kabupaten yang ada di Provinsi Jawa Barat, Indonesia yang wilayah administrasinya berbatasan sebelah utara dengan Kabupaten Ciamis (Kecamatan Banjarsari dan Kecamatan Pamarican) serta Kabupaten Tasikmalaya (Kecamatan Karangjaya dan Kecamatan Cineam), lalu di sebelah barat berbatasan dengan Kabupaten Tasikmalaya (Kecamatan Cikatomas, Kecamatan Panca Tengah, Kecamatan Cikalong dan Kecamatan Salopa) di sisi sebelah selatan berbatasan dengan Samudera Indonesia dan sisi sebelah Timur berbatasan dengan Kabupaten Cilacap (di Kecamatan Kadungreja dan Kecamatan Patimuan). Desa Margacinta merupakan salah satu desa di Kecamatan Cijulang - Kabupaten Pangandaran yang sedang dipersiapkan untuk menjadi destinasi wisata baru dengan tema desa wisata budaya (Maulana 2019). Kegiatan pengembangan desa wisata dirasa tepat untuk di terapkan di Kabupaten Pangandaran karena melihat potensi yang ada berupa budaya dan kerajinan hasil tangan buatan manusia banyak sekali selain dari keanekaragaman alamnya (Darto 2017). Beberapa daerah di Desa Margacinta yang memiliki banyak potensi sebagai desa wisata yaitu Langgong, Padek, Tirangastana, Paranje, Cibakuku, Tiranggaok, Tirangpanjang, Cijalu, Kalensakrib, Sukarenah namun yang sudah berdiri dan mantap untuk menajdi daya tarik dari desa wisata budaya Margacinta ini adalah Taman Budaya Sagati (Sagati 2019a).

\section{METODE}

Penelitian ini adalah studi kualitatif dengan metode deskriptif. Data untuk penelitian ini dikumpulkan melalui studi sastra, wawancara dan pengamatan langsung ke objek. Studi literatur ini dilakukan untuk menjadi acuan dan dasar sebagai pra-observasi setelah data yang dikumpulkan melalui wawancara dan observasi langsung ke objek, maka telah divalidasi menggunakan sumber Triangulasi dan dianalisis secara deskriptif oleh penulis.

\section{HASIL DAN PEMBAHASAN}

Taman Budaya Sagati adalah sebuah destinasi buatan yang berlokasi di Dusun Balengbeng, Desa Margacinta, Kecamatan Cijulang, Kabupaten Pangandaran. Taman Budaya Sagati adalah salah satu tujuan wisata baru di Kabupaten Pangandaran. Taman Budaya Sagati yang berlokasi di Dusun Balengbeng, Desa Margacinta, Kecamatan Cijulang, Kabupaten Pangandaran. Lokasi dari Taman Budaya Sagati sangat strategis karena berada di pinggir jalan dan memiliki tempat parkir yang lumayan luas. Taman Budaya Sagati ini mengusung konsep ramah lingkungan dan terbuka dengan panorama pohonpohon nipah, sungai dan tanaman-tanaman budidaya.

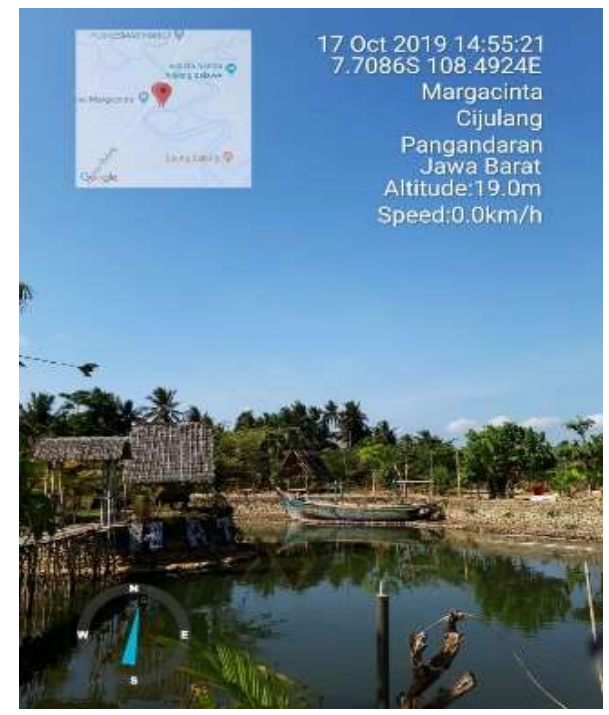

Gambar 1. Lokasi Taman Budaya Sagati (sumber: Dokumentasi pribadi, 2019)

Taman Budaya Sagati ini juga tersambung dengan Sungai Cijalu, salah satu sungai yang menjadi urat penghubung untuk lingkungan sawah dan ladang di pegunungan. Pendirian Taman Budaya Sagati ini digagas oleh Pak Edi Supardi (Kepala Desa Margacinta) dan untuk pengelolaannya dilakukan oleh swadaya masyarakat namun tetap berkerja secara bersama dengan melibatkan warga desa Margacinta dan Kelompok Sadar Wisata setempat yang dipimpin oleh Pak Edi Supardi dan beberapa tokoh lainnya (Maulana 2019).

Desa Margacinta ini khususnya di Taman Budaya Sagati memang dipersiapkan untuk menjadi daya tarik yang berbasis kearifan lokal yang bertujuan sebagai marketplace baru yang akan mengasilkan berbagai komunitas kreatif lainnya. Nantinya juga akan dikembangkan pasar kuliner khas berkualitas dari UMKM terpilih (jajanan pasar, camilan, makanan vegan segar dari tanaman yang dibudidaya oleh 
sendiri, makanan berkuah dan kukusan, oleh-oleh panganan dalam kemasaran, olahan bubur asin dan manis), pusat cinderamata dan tembakau, program one village one show (agar menjadi ikon dan ajang mengenalkan potensi daerah tersebut), penjadwalan tetap pertunjukan seni reguler (akhir pekan, khusus hari libur dan by request) serta pemberian edukasi kepada wisatawan yang datang baik nusantara dan mancanegara mengenai sejarah tradisi dan kebudayaan Sunda (Sagati 2019b).

\section{Potensi Wisata Taman Budaya Sagati}

Desa Margacinta adalah salah satu dari sekian banyak desa di Kabupaten ini beberapa diantaranya Cijulang Rafting, Wisata Mangrove, Sirkuit Metro Jaya, dan Kampung Badud untuk jenis wisata alamnya. Sedangkan, untuk wisata budaya desa ini memiliki potensi seni dan budaya berupa, Seni Badud, Seni Gondang, Seni Beluk, Seni Angklung. Seni Degung, Kecapi Suling, Seni Pongdut, Seni Wayang Golek, Seni Reog, Seni Qosidah dan Pengrajin Angklung. Di objek Wisata Taman Budaya Sagati ini pengunjung dapat menikmati kuliner tradisional (nasi liwet jolem ikan, karedok kecombrang, jus kecombrang), merasakan bumbu-bumbu masakan tradisional khas Sunda, melihat budaya masak tradisional beserta alat-alat masak yang kini sudah jarang digunakan, serta ada pula fasilitas hiburan yaitu perahu-perahu kecil yang dapat disewa untuk mengarungi sungai Cijalu Hilir yang dapat menjadi salah satu daya tarik sekunder dari Taman Budaya Sagati ini. Apabila mengarungi sungai ini hingga ke hulu maka kita akan sampai ke Green Canyon yang berada di daerah kecamatan Parigi.

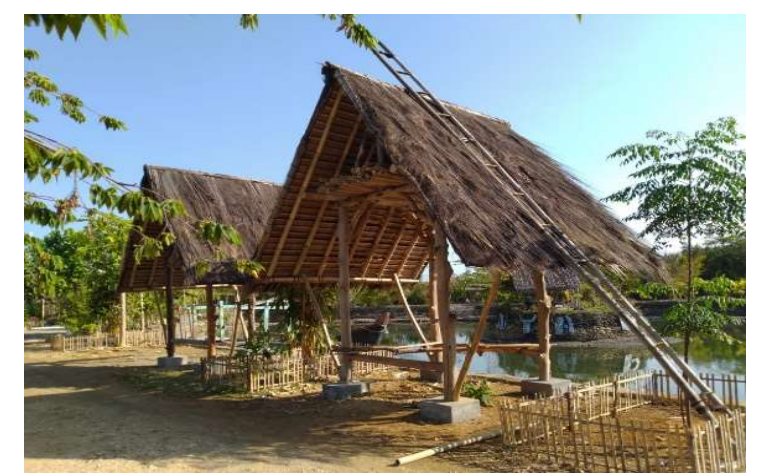

Gambar 2. Taman Budaya Sagati (sumber: Dokumentasi pribadi, 2019)

Kegiatan-kegiatan yang digadangkan menjadi daya tarik utama dari Taman Budaya Sagati pada saat ini yaitu penampilan dan pemahaman dari unsur budaya agraris masyarakat yang berdampingan dengan lingkungan dan budaya pesisir. Disamping itu, Taman Budaya Sagati juga direncanakan kedepannya akan dijadikan sebagai salah satu tempat wajib untuk di kunjungi serta berpeluang untuk menjadi sentral berkumpulnya wisatawan sebelum menyebar ke berbagai tujuan wisata yang ada di Pangandaran.

Desa Margacinta khususnya Taman Budaya Sagati ini akan dijadikan sebagai pusat untuk kebudayaan di Kabupaten Pangandaran yang kedepannya akan menjadi salah sentral atau etalase untuk pelestarian kebudayaan Sunda, pameran kerajinan dan juga menampilkan perhelatan seni diantaranya seperti tarian Ngecak, Beuluem Kurumus, Ngajodang, Ngaronggeng, Badud, Lebon, Moro, Panen, Performance Calung Renteng, Beluk, Reog, Wayang Golek, Rudat, Silat, Atraksi Parahu, Jingkrung (kesenian seperti menyanyikan puji-pujian kepada Allah SWT sebagai tanda syukur atas rezeki) Kaulinan Barudak dan lainnya (Maulana 2019).

\section{Kearifan Lokal Dan Pelibatan Masyarakat Di Taman Budaya Sagati sebagai Upaya Pelestarian Budaya}

Masyarakat adalah sekelompok orang yang saling mendukung dalam satu tempat yang sama secara geografis atau unit sosial dimana orang mengidentifikasikan diri mereka sebagai anggota masyarakat dimana nantinya bisa mengambil keputusan secara komunal (Salazar 2012). Gagasan, nilai ataupun pandangan yang muncul dan bekembang dari internal suatu daerah yang bernilai baik dan diikuti serta dipercayai oleh masyarakat tersebut dan diwariskan secara turun temurun disebut dengan kearifan lokal (Akbar 2017). Masyarakat dan budaya kearifan lokal yang ada pada suatu daerah memegang peranan penting dalam arah perkembangan dan kemajuan dari kegiatan pariwisata di suatu destinasi (Salazar 2012). Pelibatan masyarakat, pengangkatan dan pelestarian kearifan lokal merupakan kunci penting yang membuat sebuah destinasi itu memiliki nilai lebih.

Berada di jaman yang modern serba digtalisasi ini, mudahnya mengakses informasi dari manapun dan maraknya kebudayaan serta tren baru yang bermunculan tidak serta merta menjadikan masyarakat Desa Margacinta terbawa pengaruh tersebut. Desa Margacinta khususnya masyarakat sekitar Taman Budaya Sagati memiliki cara sendiri untuk tetap dapat bertahan dan mengakomodasi namun tidak terlalu pengaruh budaya luar dengan cara menjaga atau membentengi diri dengan berpegang teguh pada kearifan lokal yang dimilikinya.

Di Desa Margacinta khususnya di Taman Budaya Sagati, nilai-nilai kearifan lokal ini masih sangat dijaga dan dilakukan dalam kehidupan sehari-hari. Beberapa nilai kearifan lokal yang dapat dilihat di Taman Budaya Sagati ini adalah kebiasaan untuk selalu tersenyum dan memperlakukan siapapun yang 
datang seperti keluarga sendiri, saling membantu untuk kegiatan pengelolaan dan operasional, pembiasaan hidup sederhana tidak berlebihan dalam rangka salah satu cara pengendalian diri juga pertahanan dari pengaruh budaya luar, serta penggunaan alat-alat dan cara tradisional dalam berbagai hal (untuk memasak, alat-alat yang digunakan untuk berkebun, budaya bekerja) sesuai dengan kebudayaan Sunda.

Masyarakat sekitar juga turut berperan aktif dalam dilibatkan dalam kegiatan pengelolaan dan operasional di Taman Budaya Sagati ini. Hingga saat ini, beberapa contoh dari pelibatan tersebut yaitu baru sebatas bantuan bergotong royong dalam perenovasian dan peningkatan fasilitas di Taman Budaya Sagati, peluang untuk mendapat tambahan pemasukan dengan memberi kesempatan untuk menyediakan makanan dan minuman yang khas dari Desa Margacinta (jus kecombrang, karedok kecombrang dan nasi jolem, nugget jantung pisang, dodol singkong, singkong goreng, pisang goreng), budidaya tanaman tradisional yang dapat dijual dan digunakan sendiri, dapat menjadi pemandu apabila ada wisatawan yang datang, ikut dalam kegiatan kreatif yang dilakukan (pembuatan kerajinan untuk cinderamata dari Taman Budaya Sagati), serta berpartisipasi aktif untuk mendukung adanya pagelaran seni atau kerajinan yang diadakan di Desa Margacinta khususnya Taman Budaya Sagati.

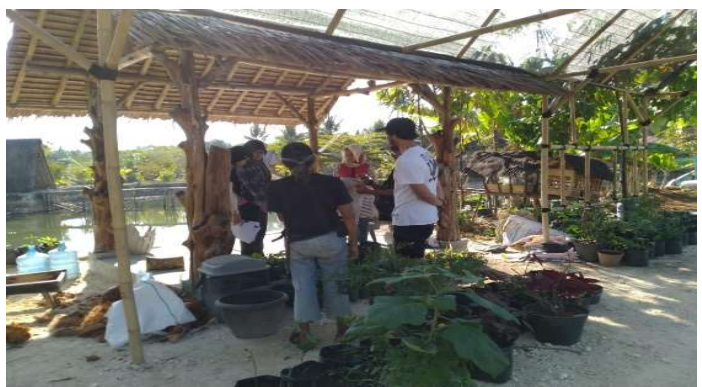

Gambar 3. Budidaya tanaman tradisional di Taman Budaya Sagati (sumber: Dokumentasi pribadi, 2019)

Kegiatan pelibatan masyarakat yang utama ingin dikembangan oleh Taman Budaya Sagati ini adalah untuk peningkatan usaha yang terkait dengan bidang pariwisata kreatif. Taman Budaya Sagati ini sudah memiliki beberapa produk kerajinan yang kualitasnya baik dan mulai dikenal walaupun baru dalam lingkup kecil dan tertentu. Hasil produknya untuk sementara yaitu gelang-gelang dan kalung dari tanaman serta kerang, kreasi padud (seperti cangklong untuk merokok atau hiasan), tempat abu rokok (dari batok kelapa dengan ornamen lainnya), topi-topi caping kayu, klotok (lonceng untuk ternak) dan masih akan terus dikembangkan kedepannya. Namun yang menjadi hambatan adalah kurangnya sumber daya manusia yang mumpuni serta ketrbatasan waktu dan tenaga yang dimiliki oleh pengerajin sehingga belum dapat optimal.

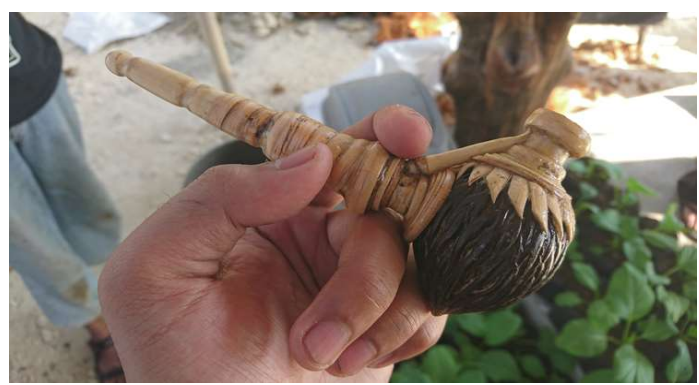

Gambar 4. Kreasi Padud (sumber: Dokumentasi pribadi, 2019)

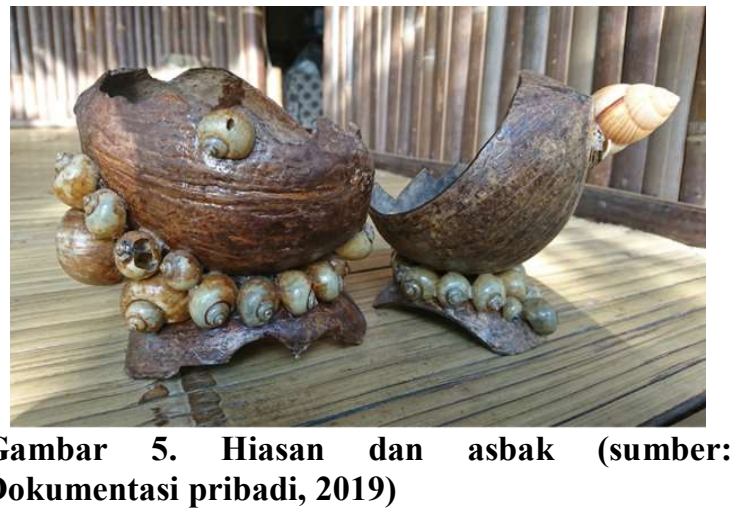

Pengembangan dan pelestarian budaya Sunda di Taman Budaya Sagati tidak hanya dilakukan oleh Pak Edi Supardi sebagai pemilik dan teman-teman pengelola saja, namun banyak pula pihak lainnya yang telibat. Masyarakat Desa Margacinta, masyarakat daerah Kecamatan Cijulang dan Parigi serta beberapa kelompok sadar wisata yang ada di Kabupaten Pangandaran ikut membantu berperan aktif dalam prosesnya (Maulana 2019).

Daya tarik yang ada di di Desa Margacinta ini mendapat banyak bantuan dalam pengembangannya oleh Kompepar Margacinta. Kompepar Margacinta ini sangat aktif dalam mengembangkan potensi kepariwisataan terutama bidang potensi alam, seni dan budaya serta dalam mempertahankan juga menjaga kearifan lokal Desa Margacinta (Maulana 2019). Cara yang dilakukan oleh Kompepar Margacinta dalam rangka melakukan pelestarian budaya ini yaitu dengam cara bekerjasama dengan Pak Edi Supardi dan pengelola Taman Budaya Sagati lainnya untuk minimal sekali pada akhir minggu dan lebih gencar pada hari khusus untuk mengadakan perhelatan atau pentas budaya lokal. Pagelaran yang ditampilkan diantaranya yaitu pagelaran badud (berkerjasama 
dengan Kampung Badud), pencak silat, ronggeng gunung, ronggeng dan tak lupa pula angklung berkerja sama dengan Saung Angklung Mang Koko.

\section{SIMPULAN}

Secara umum, Taman Budaya Sagati memiliki nilai lebih dalam hal sumber daya, ide dan inovasi. Namun Taman Budaya Sagati belum mampu mengelola ketiga poin tersebut sehingga masih belum terlalu terlihat. Penataan tempat masih belum rapi (banyak seperti masih renovasi atau belum selesai bangunannya), sarana dan prasarana masih kurang, pengelolaan masih belum terarah, sumber daya manusia yang kompeten masih kurang, sehingga potensi yang ada belum dapat dimaksimalkan.

Walaupun kegiatan pemberdayaan masyarakat di Taman Budaya Sagati ini sudah dapat dikatakan baik namun tetap saja sebaiknya dilakukan programprogram lain yang dapat membantu pengoptimalan pemberdayaan ini yaitu berupa penyuluhan, audiensi, pendampingan dan pembinaan terjadwal bersama pihak pemerintah (Kecamatan, Kabupaten dan instansi terkait seperti Dinas Pariwisata) - tokoh masyarakat masyarakat setempat dengan pengelola lalu pendataan secara berkala untuk memperbarui data potensi desa serta pembuatan kajian untuk pengembangannya.

Taman Budaya memiliki banyak tugas bebenah dari manajerial dan pengadaan fasilitas untuk dapat menjadi sebuah daya tarik baru yang mampu mendatangkan banyak wisatawan dan dapat mencapai tujuan di dirikannya yaitu menjadi salah satu tempat pusat kebudayaan di Kabupaten Pangandaran yang dapat menjadi percontohan budaya di Provinsi Jawa Barat dan dapat mengangkat kesejahteraan hidup warganya. Dalam pengembangannya, Taman Budaya Sagati dan Desa Margacinta perlu untuk lebih aktif berkerjasama dan bersinergi dengan pihak-pihak terkait untuk pengadaan kajian-kajian lebih lanjut mengenai perencanaan tata kelola, pengembangan daerah dan pemberian penyuluhan ataupun bantuan terkait pengoptimalan serta pembekalan untuk peningkatan kualitas sumber daya. Penguatan tata keloa, pengembangan pasar, pembentukan citra, pengemasan potensi yang ciamik, promosi dan penguatan kemitraan merupakan kunci sukses bagi Taman Budaya Sagati agar mampu menjadi ikon baru kebudayaan untuk Provinsi Jawa Barat yang memiliki nilai berdaya saing tinggi.

\section{DAFTAR PUSTAKA}

Darto. 2017. "Pemberdayaan Masyarakat Dalam Upaya Pengembangan Desa Wisata Di Kecamatan Cijulang Kabupaten Pangandaran Provinsi Jawa Barat." Majalah Imiah UNIKOM 15 (1): 61-70.

Markwick, Marion. 2018. "Valletta ECoC 2018 and Cultural Tourism Development." Journal of Tourism and Cultural Change 0 (0): 1-23. https://doi.org/10.1080/14766825.2017.129367 4.

Maulana, Muhammad Iqbal. 2019. "Pengembangan Pariwisata Kreatif Di Kampung Badud - Desa Margacinta."

Nahak, Hildigardis M I. 2019. "Upaya Melestarikan Budaya Indonesia Di Era Globalisasi." Sosiologi Nusantara 2 (1): 65-76.

Rahmi, Siti Atika. 2016. "Pembangunan Pariwisata Dalam Perspektif Kearifan Lokal." REFORMASI 6 (1): 76-84.

Salazar, Noel B. 2012. "Community-Based Cultural Tourism : Issues , Threats and Opportunities." Journal of Sustainability Tourismy Tourism, no. March 2013: 37-41.

Sugiyarto, and Rabith Jihan Amarul. 2018. "Pengembangan Pariwisata Berbasis Budaya Dan Kearifan Lokal." Jurnal Administrasi Bisnis 7: 45-52.

Adriani, Yani. 2017. "Kajian Potensi Pariwisata Jawa Barat 2017.”. Pusat Perencanaan dan Pengembangan Kepariwisataan Institut Teknologi Bandung.

Akbar, Firman. 2017. "Kearifan Lokal,".

Ranawati, Nur Khansa. 2019 September. "Setahun Emil-Uu: Pariwisata Jabar Digenjot.”. Ayo Bandung.com . Bandung. Retrieved from www.ayobandung.com

Sagati, Pengelola Taman Budaya. 2019a. "Pembangunan Daya Tarik Wisata Desa Margacinta."

—. 2019b. "Sagati: Culinary \& Cultural Performance."

Syarifah, Fitri. 2019. "Mantap Jadi Provinsi Pariwisata, Jabar Rilis West Java Calender of Event 2019,". 